\title{
Treatment of Retained DJ(neglected DJ) in AL-Anbar Government, A Postconfict Study
}

\author{
Omar Mahmood Shakir ${ }^{1}$; Dhia A.Kareem ${ }^{2}$; Ameel Farooq Al Shawi ${ }^{3}$, Wafaa Khalel Ibrahim ${ }^{4}$ \\ ${ }^{1}$ College of Medicine, University of Fallujah, Urosurgeon, AL-Fallujah teaching hospital ,Iraq; ${ }^{2}$ Urosurgeon, \\ AL-Ramadi teaching hospital, Iraq, ${ }^{3}$ Department of Community \& Family Medicine, College of Medicine, \\ University of Fallujah, Iraq; ${ }^{4}$ Department of pathology, College of Medicine, University of Anbar, Iraq
}

\begin{abstract}
Double J ureteral stents have been used to relieve or improve drainage in cases of ureteric obstruction from any causes (intrinsic or extrinsic). These forgotten or retained ureteral stents could lead to many complications. The objective of the paper is to assess the methods that used for treatment of neglected double Jamong displaced persons. Across section study was done, 28 patients with neglected double J stent were chosen from urology departments in Al-Ramadi \& Al-Fallujah teaching hospitals. Result: Out of total (28) , $20(71.4 \%)$ were males while females were $8(28.6 \%)$ of the sample. The indication of insertion varied between $13(46.4 \%)$ patients after Ureterorenoscopy procedure for ureteric stones (10 males \& 3 females ) and five $(17.9 \%)$ patients due to traumatic causes, four (14.3\%) patients due to pyelolithotomy , three (10.7\%) patients PNL for removal of renal stone. The complications rare which ranged from fever postoperatively in nine patients $(32.1 \%)$, two patients $(7.1 \%)$ suffered from ureteric injury thatmandate double $\mathrm{J}$ insertion, three patients $(10.7 \%)$ required more than two sessions to clear the ureter \& remove of retained double $\mathrm{J}$.
\end{abstract}

Keywords: Forgotten DJ, complications, Anbar governorate.

\section{Introduction}

Since their introduction into clinical use for first time in 1967 ,Ureteral stents have been widely utilized for many urological indications. ${ }^{[1]}$

Double J (DJ) ureteral stents have been used to relieve or improve drainage in cases of ureteric obstruction from any causes (intrinsic or extrinsic). They used also after iatrogenic injuries to the ureter during ureterorenoscopy (URS) and also after various operation in ureter \&renal pelvis ${ }^{\cdot[2]}$

Over the lastyears \&with improvement in technology of stent material \&design, the patient complaint from DJ will decrease. As a result, DJ stents have been left in place for a longer duration of time. ${ }^{[3]}$

\section{Corresponding author: \\ Omar Mahmood Shakir \\ drnihadkhalawe@gmail.com ; \\ omermhmod@yahoo.com}

These forgotten or retained ureteral stents could lead to many complications such as up or down slipping , fragmentation, encrustation and stone formation. ${ }^{[4-6]}$.

Encrustations are most frequently noted in forgotten/retained DJ's, that stay in body for longtime. The causes of encrustation is multifactorial. Most common risk factors for encrustation of DJ are long time duration of stenting, urinary tract infection, past history urinary stones disease, such chemotherapy\&chronic renal disease ${ }^{[7]}$

For remove the severely encrusted DJ stent there is many procedures as (shock wave lithotripsy (SWL), ureterorenoscopy, cystolitholepaxy and even percutaneous nephrolithotomy (PCNL ) or open surgery according to patient condition \& site of encrustation..[8,9]

The treatment depend on patient condition (encrustation site, stone burden ,fragmentation of DJ.... etc), availability of equipment \&Endourological tools \& 
experience of surgeon .

Iraqi health system is suffering due to wars, sanctions and violence. Iraq and Iraqis exposed to widespread violence since 2003 , that violence became a leading cause of death for Iraqi adults after March 2003 and the main cause for men aged 15-59years. ${ }^{[10]}$

The condition was deteriorated in June 2014 as several governorates in west and north of Iraq especially our governorate (AL- Anbar) were invaded by ISIS , the harm was huge, several reports documentedthat an extensive damage was occurred to the infrastructures of these provinces especially in health and teaching sectors left many hospitals and health care centers became out of work, in addition to that thousands of people were displaced to refugees camps in different regions including Kurdistan -north of Iraq- in which they lack the basic health services, they loss ability to manage their health disorders and they didn't find the special care for emergency conditions such as surgical operations.

So there were many patients neglected (not forget DJ) in there body especially those people who lived in camps for prolong periods might be months or years without receiving heath care.

After end of war \& family retuned to AL-Anbar governorate ,the our teaching hospital (AL-Ramadi \& AL-Fallujah) were receive many cases of neglected DJ ,\&we decided to share our experience to world about this rare conditions.

The objective of the paper is to assess the methods that used for treatment of neglected DJ among displaced persons.

\section{Material and Methods}

Study design and period

Across sectional study was carried out during the period of from March 2017 to April 2019 (after end of war with ISSI) were included in this study.

Sample size and sampling technique

Convenience sample of 28 patients with neglected DJ stent were chosen from Urology Department in Al-Ramadi teaching hospital \& Al-Fallujah teaching hospital (in Al-Anbar government)
The inclusion criterion was

1. Patient with more than 6 months duration of the stenting.

2. No malignant obstruction require prolong stenting.

\section{Data collection procedures and instruments}

Assessment of patients was done via questionnaires that contain age, sex, indication of stenting, chief complaint of patient, The indwelling time of the stent was measured from the time of stent insertion to time of stent removal, need of preoperative SWL , Procedure required \&any complications occur during complications.

Kidney-ureter-bladder (KUB) x-ray and ultrasound of urinary system (US) were performed in all patients to evaluate the patient anatomical details, severity of encrustation, size \&site of related stone, and any other complexity of the situation (e.g., broken or migrated stent).

A non-contrast computerized tomography (NCCT) and/or intravenous pyelography were perfumed to selected patient according to availability \&if more details are needed.

The preoperative evaluation consisted of : A urine exam .; Blood urea \& serum creatinine; Complete blood picture ; In patients with positive infection in urine exam results, an urine culture performed \& intervention was postponed after antibiotic treatment ; Viral screen and Other investigation need according to patient age \&comorbidity such as random blood sugar, liver function test ,Echocardiography (ECG) ,.....etc.

All patients received preoperative antibiotic.

Treatment decisions were made on the basis of radiological findings and the clinical findings \& availability of various treatment modalities

Patients needed various endourologic procedures under general or local anesthesia in one or more sessions.

To remove the stent and related stone burden, various combinations of the following were used:

1. Extracorporeal Shockwave lithotripsy (ESWL) :was performed using the Siemens Lithostar Modularis 
AG Healthcare,

Munich, Germany.

2. Simple cystoscopic stent removal:under local or general anesthesia by cystoscopy $22 \mathrm{~F}$ for adult \& $13 \mathrm{~F}$ pediatric cystoscopy .

3. Ureterorenoscopy (URS): The URS was done using $6 \mathrm{~F} / 7.5 \mathrm{~F} \& /$ or $9 \mathrm{~F} / 12 \mathrm{~F}$ Storz semirigid

ureteroscopes with using EMS pneumatic lithotripter or A Quanta holmium laser as an intracorporeal lithotripter.

4. Cystolitholepaxy :mourmyers lithotripter for adult \& ureteroscopes with using EMS pneumatic lithotripter or A holmium as an intracorporeal lithotripter for children .

5. Open surgery :Pyelolithotomy, Ureterlithotomy

KUB and urinary system US were used to assess the postoperative residual stone burden. Patients suspected of having residual stones or hydronephrosis were evaluated by NCCT. Patients were considered stone-free if the postoperative imaging studies revealed no residual stones more than $3 \mathrm{~mm}$.

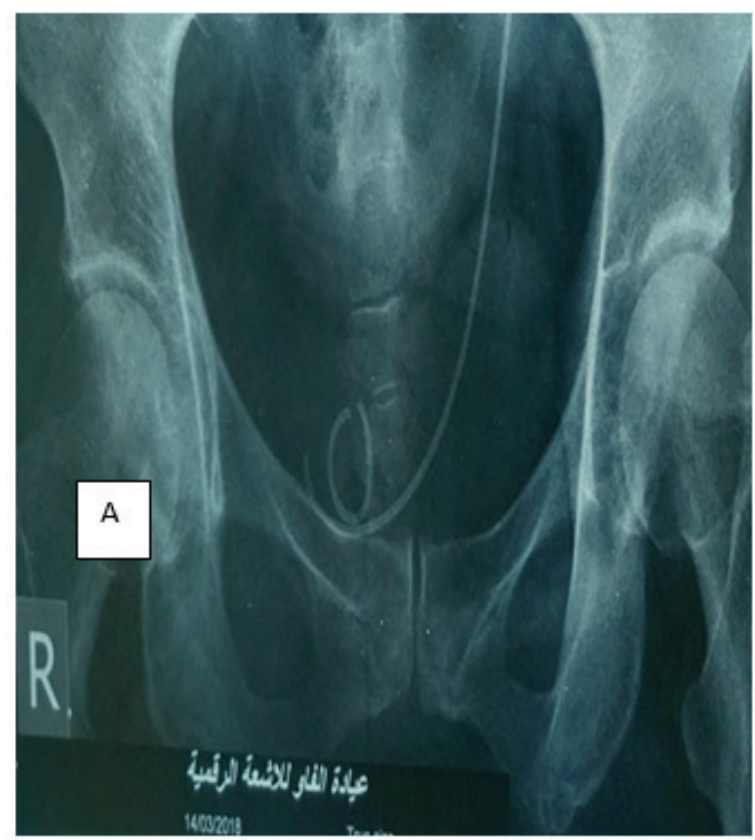

Aim of the study was explained to the participant \&written consent was obtained from them.

\section{Findings}

Out of total $(28), 20(71.4 \%)$ were males while females were $8(28.6 \%)$ of the sample.

Age of the subjects was between 5-61years ( mean of $35.25+16.8$ )

The indication of insertion varied between 13 $(46.4 \%$ ) patients after URS procedure for ureteric stones (10 males \& 3 females ) and five (17.9\%) patients due to traumatic causes, four $(14.3 \%)$ patients due to pyelolithotomy, three $(10.7 \%)$ patients PCNL for removal of renal stone. DJ indwelling time ranged between 7-36 months (mean of 16.79+-9.2)

The most presenting complaint was lower urinary tract symptoms(LUTS )which stated by 18 $(64.3 \%)$ patients and loin pain was reported by five $(17.9 \%)$ patients while three $(10.7 \%)$ patients were asymptomatic.

The results reported that five (17.9\%) patients need prior SWL

ospital .

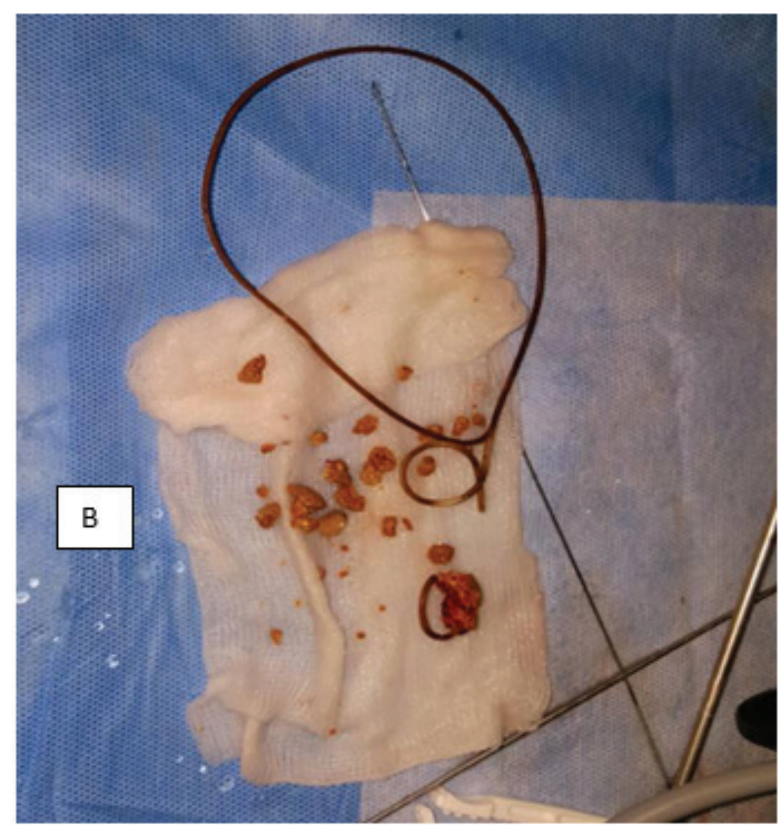

Figure 1: Female patient with fragmented DJ A. Before Removal B. After Removal. 

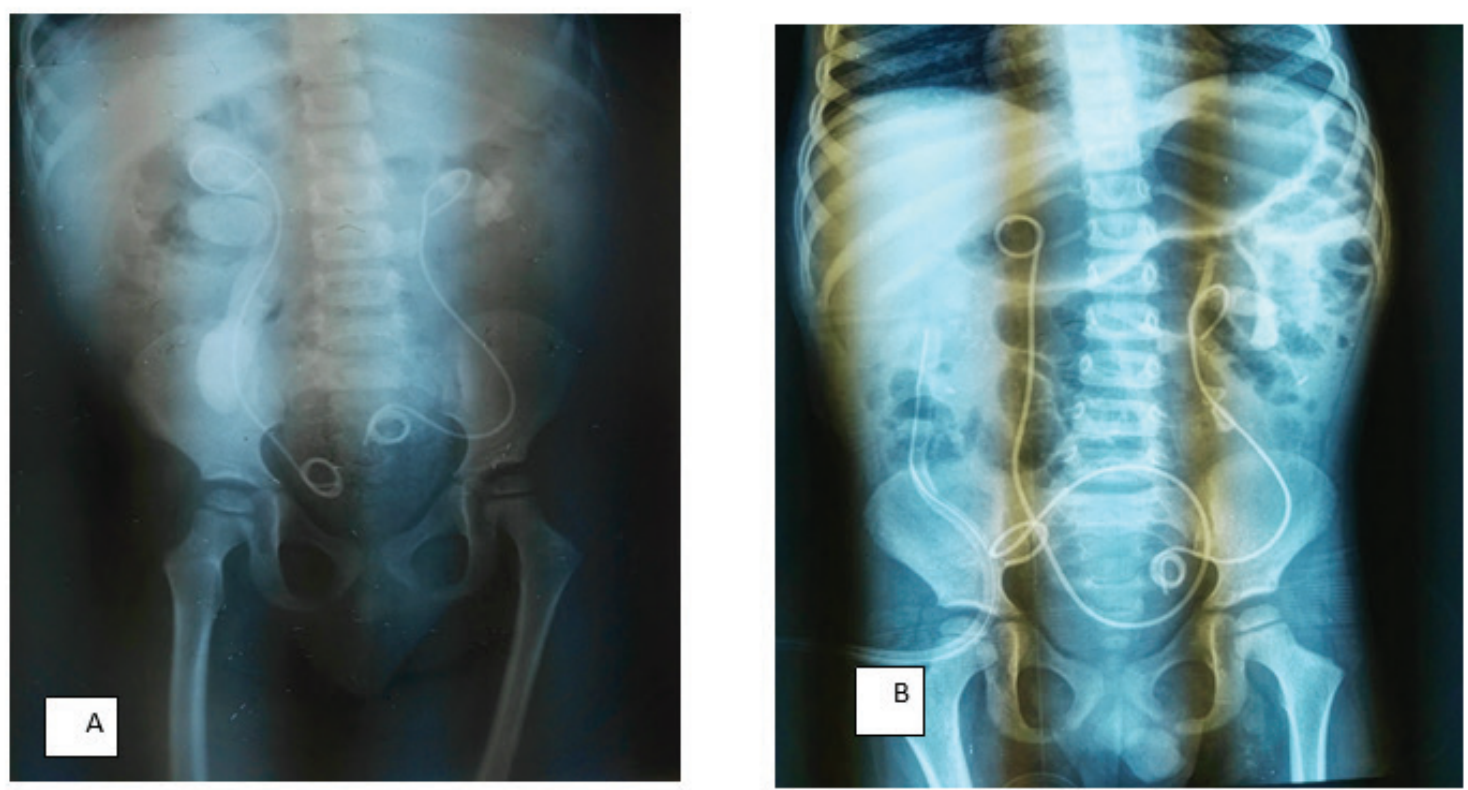

Figure2: A. Before operation B. After open surgery.

Regarding procedure, the results showing that 17 (60.7\%) patients need URS with laser lithotipsy \& one (3.6\%) patient underwent URS with pneumatic lithotipsy, alone or company with cystolitholepaxy in two (7.1\%) patients (Table 1).

Table 1 : Association of gender with indication, complaint ,procedure \& complications

\begin{tabular}{|c|c|c|c|}
\hline & & $\mathbf{N}$ & $\%$ \\
\hline \multirow{5}{*}{ Indication } & PNL & 3 & 10.7 \\
\hline & URS & 13 & 46.4 \\
\hline & Pyelolithotomy & 4 & 14.3 \\
\hline & Trauma (iatrogenic \&non iatrogenic ) & 4 & 14.3 \\
\hline & Others & 4 & 14.3 \\
\hline \multirow{5}{*}{ C. complaint } & LUTS & 18 & 64.3 \\
\hline & Hematuria & 1 & 3.6 \\
\hline & Flank pain & 5 & 17.9 \\
\hline & Asymptomatic & 4 & 14.3 \\
\hline & Total & 28 & 100.0 \\
\hline \multirow{3}{*}{ SWL } & Yes & 5 & 17.9 \\
\hline & No & 23 & 82.1 \\
\hline & Total & 28 & 100.0 \\
\hline
\end{tabular}


Cont... Table 1 : Association of gender with indication, complaint, procedure \& complications

\begin{tabular}{|c|c|c|c|}
\hline \multirow{8}{*}{ Procedure } & Simple cystoscopic stent removal & 6 & 21.4 \\
\hline & Cystolitholepaxy & 1 & 3.6 \\
\hline & URS Pneumatic lithotripsy & 2 & 7.1 \\
\hline & Holmium laser & 16 & 57.1 \\
\hline & Pyelolithotomy & 1 & 3.6 \\
\hline & Ureterolithotomy & 1 & 3.6 \\
\hline & Both & 1 & 3.6 \\
\hline & Total & 28 & 100.0 \\
\hline \multirow{5}{*}{ Complications } & Without & 14 & 50.0 \\
\hline & Fever & 9 & 32.1 \\
\hline & Ureteric injury need DJ insertion & 2 & 7.1 \\
\hline & Need multiple sessions & 3 & 10.7 \\
\hline & Total & 28 & 100.0 \\
\hline
\end{tabular}

Six (21.4\%) patients need only gentle cystoscopy removal by forceps, while three $(10.7 \%)$ patients need open surgery, one pyelolithotomy \&other uretrolithotmy (Table 1)

$\&$ most difficult case was child in 5years old need combined open pyelolithotomy \& ureterolithotomy $\&$ pneumatic litholepaxy due to huge stone burden in kidney \&ureter(Fig 2).

The complications rare which ranged from fever postoperatively in nine patients $(32.1 \%)$, two patients (7.1\%) suffered from ureteric injury that mandate DJ insertion, three patients (10.7\%) required more than two sessions to clear the ureter \& remove of retained DJ ( Table 1).

In our study we had only one case with fragmented DJ (Fig. 1)

Statistically ,there was non-significant association between gender and procedure required or complications

The results revealed that statistically non-significant association between indications of DJ insertion \& type of procedure that required \& complications ( Table 2 ).

Table 2: Relation between indication of DJ insertion \&procedure used

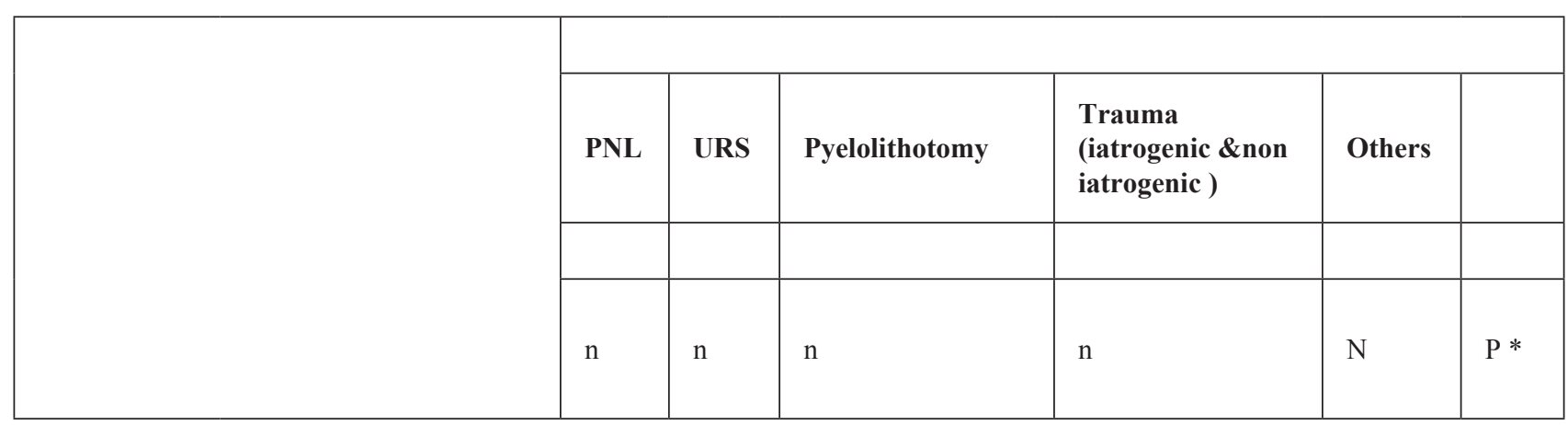


Cont... Table 2: Relation between indication of DJ insertion \& procedure used

\begin{tabular}{|c|c|c|c|c|c|c|c|}
\hline \multirow{5}{*}{ Procedure } & $\begin{array}{l}\text { Simple cystoscopic stent } \\
\text { removal }\end{array}$ & 1 & 2 & 2 & 1 & 0 & 0.98 \\
\hline & Cystolitholepaxy & 0 & 1 & 0 & 0 & 0 & \\
\hline & $\begin{array}{l}\text { URS Pneumatic } \\
\text { lithotripsy }\end{array}$ & 0 & 1 & 0 & 1 & 0 & \\
\hline & Holmium laser & 2 & 6 & 2 & 2 & 4 & \\
\hline & Pyelolithotomy & 0 & 1 & 0 & 0 & 0 & \\
\hline \multirow{4}{*}{ C. Complaint } & Hematuria & 1 & 8 & 4 & 2 & 3 & \\
\hline & LUTS & 0 & 1 & 0 & 0 & 0 & 1.62 \\
\hline & Flank pain & 2 & 0 & 0 & 2 & 1 & \\
\hline & Asymptomatic & 0 & 4 & 0 & 0 & 0 & \\
\hline
\end{tabular}

*P of chi square test

The findings revealed that statistically insignificant association between time of indwelling DJ \&complications.

\section{Discussion}

Although the uses of DJ increasing nowadays \&with effectiveness in treatment of many urological problems and prevent many complications but it might be associated with several complications such as LUTS , hematuria ,up or down slipping \&encrustation especially in retained DJ $\cdot[11]$

The encrustation of neglected stents with a severe stone burden is a serious complications due to recurrent infections, hematuria, obstructive uropathy \& even renal failure.[11]

Though there has been no definition for "forgotten" as any such term does not exist, but many previous studies consider a variable period of greater than 3 to 6 months to be considered as a forgotten stent ${ }^{[12]}$
The treatment of retained or neglected DJ is a challenging procedure \&need individualization of cases.

The literature has been shown that poor compliance is the major concern, which leads to forgotten DJ stent in situ ${ }^{[13]}$

Anbar governorate suffered from invasion of ISSI,thousands of people were displaced to camps without basic health services after end of war they consult our hospital for removal this DJ, the health system suffered from damage of infra- structure \&lack of equipments. The patients with DJ were neglected for years. The results revealed that the mean of indwelling time was (16.79+-9.2) months , a study that conducted by Okuda et al revealed that the mean indwelling times of these stents was 20 months ${ }^{[14]} \&$ other study reported the mean indwelling time of the DJS was $22.6 \pm 30.3$ (6-144) months ${ }^{[15]}$

The maximum DJ indwelling time in literature was 23 years while in our study, the maximum duration was 
of 3 years $^{[2]}$

The most presenting complaint was LUTS which stated by $(64.3 \%)$ patients followed by $(17.9 \%)$ patients suffered from loin pain while $(10.7 \%)$ patients were asymptomatic.This finding was inconsistent with results of Damiano et al who observed flank pain in $25.3 \%$, encrustations in $21.6 \%$, LUTS in $18.8 \%$, hematuria in $18.1 \%$, fever more than $104^{\circ} \mathrm{F}$ in $12.3 \%$ and stent migration in $9.5 \%$ of the patients. ${ }^{[16]}$.

The most indication of DJ insertion was $(46.4 \%)$ patients after URS procedure for ureteric stones, $(17.9 \%$ ) patients due to traumatic causes, \& (14.3\%) patients due to pyelolithotomy while in study of Senol etal were Urolithiasis in $83.3 \%$, hydronephrosis in pregnancy in $9.2 \%$, surgical procedures in ureter in $5.5 \%$, and renal transplantation in $8 \% .^{[15]}$

In the literature,the fragmentation of ureteral stents was $0.3-10 \%{ }^{[4,6]}$ In our findings , the fragmentation rate was $3.57 \%$.

Although there was obvious increase in complication of removal retained DJ with increase of indwelling time but it failed to reach significant statistically may be due to small sample size .

In first step, we did KUB \&US to the patients ,if no obvious encrustation we used gentle trial of removal DJ without forces to avoid any complications such as ureteral injury, this succeed with six patients, if this procedure failed then we sent the patient to NCCT to evaluated the site of encrustation \&stone burden \&any other complications, if mild to moderate encrustation that localized to pelvis or upper ureter, we sent him to SWL before endourological procedure done if encrustation along DJ or in lower end of DJ we did endourological procedure.

At first we evaluated the lower coil of DJ, if encrustation was found then we fragmented it by mourmyer stone crusher for adults.

If encrustation around DJ in ureter, we introduced simirigid URS in between ureteral wall \&DJ \& fragmentation occur by laser or pneumatic lithotipsy with remove of small fragment by forceps. if there was obvious ureteric injury, we inserted DJ for 4 weeks durations, such conditionoccurred in two patient
(7.14\%).

If there was severe encrustation in kidney which occurred in 2 cases, we used open surgery because PNL not available in our hospital .

\section{Conclusion}

Forgotten/neglected DJ can lead to wide range of complications from simple lower urinary tract symptoms to the loss of renal function. The treatment of retained or neglected DJ (as in our study) is a challenging procedure \&need individualization of cases. international algorithm might be needed to treated such difficult situation. Health education about serious complications that may occur due to longtime DJ insertion.

\section{Conflict of Interest: Non}

Source of Findings: Self Findings.

Ethical Clearance: Non

\section{References}

1. Zimskind PD, Fetter TR, Wilkerson JL. Clinical use of long-term indwelling silicone rubber ureteral splints inserted cystoscopically. J Urol. 1967;97: 840-844.

2. Borboroglu PG, Kane CJ. Current management of severely encrusted ureteral stents with a large associated stone burden. J Urol. 2000;164(3 Pt 1):648-50.

3. Beiko DT, Knudsen BE, Denstedt JD. Advances in ureteral stent design. J Endourol. 2003;17:195-199.

4. Monga M, Klein E, Castañeda-Zúñiga WR, Thomas R. The forgotten indwelling ureteral stent:A urological dilemma. J Urol. 1995;153:1817-9.

5. Sancaktutar AA, Soylemez H, Bozkurt Y, et al. Treatment $€$ of forgotten ureteral stents: How much does it really cost? A cost-effectiveness study in 27 patients. Urol Res. 2012;40:317-325.

6. El-Faqih SR, Shamsuddin AB, Chakrabarti A, Atassi R, Kardar AH, Osman MK, et al. Polyurethane internal ureteral stents in treatment of stone patients: Morbidity related to indwelling times. J Urol. 1991;146:1817-20.

7. Bultitude MF, Tiptaft RC, Glass JM, et al. Managementof encrusted ureteral stents impacted in upper tract.Urology. 2003;62:622-626. 
8. Somers WJ. Management of forgotten or retained indwelling ureteral stents. Urology. 1996;47:431435.

9. Rana AM, Sabooh A. Management strategies and results for severely encrusted retained ureteral stents. J Endourol. 2007;21:628-32.

10. WHO https://www.who.int/mediacentre/news/ releases/2008/pr02/en/

11. Singh V, Srinivastava A, Kapoor R, et al. Can the complicated forgotten indwelling ureteric stents be lethal? Int Urol Nephrol. 2005;37:541-546.

12. Sohrab A, Aneesh S, Sureka SK. Forgotten Reminders: An Experience with Managing 28 Forgotten Double-J Stents and Management of Related Complications. Indian J Surg. 2015;77:1165-71.
13. Murthy KV, Reddy SJ, Prasad DV. Endourological management of forgotten encrusted ureteral stents. Int Braz J: Off J Braz Soc Urol. 2010;36(4):420-9.

14. Okuda H, Yamanaka M, Kimura T, Takeyama M. Case of multiple encrusted stones on the ureteral stent left for 7 years: the efficacy of extracting the ureteral stent on transurethral lithotripsy. Nihon Hinyokika Gakkai Zasshi. 2009;100(6):635-9.

15. Adanur S, Ozkayasenol F. Challenges in treatment and diagnosis of forgotten/encrusted double-J ureteral stents: the largest single-center experience. Renal Failure Journal .2016; 38:6, 920-926.

16. Damiano R, Oliva A, Esposito C, De Sio M, Autorino R, D'Armiento M. Early and late complications of double pigtail ureteral stent. Urol Int. 2002;69(2):136-40. 